\title{
Metalation/De-metalation as a Post-Gelation Strategy to Tune the Mechanical Properties of Catenane-Crosslinked Gels
}

\author{
Mark A. Nosiglia, Nathan D. Colley, Mark S. Palmquist, Abigail O. Delawder, Sheila L. Tran, \\ Gray H. Harlan, Jonathan C. Barnes*
}

Department of Chemistry, Washington University, St. Louis, Missouri 63130, United States

Supporting Information Placeholder

\begin{abstract}
Mechanically interlocked molecules (MIMs) possess unique architectures and non-traditional degrees of freedom that arise from well-defined topologies that are achieved through precise mechanical bonding. Incorporation of MIMs into materials can thus provide an avenue to discover new and emergent macroscale properties. Here, the synthesis of a phenanthroline-based [2]catenane crosslinker and its incorporation into polyacrylate organogels is described. Specifically, $\mathrm{Cu}(\mathrm{I})$ metalation and de-metalation was used as a post-gelation strategy to tune the mechanical properties of a gel by controlling the conformational motions of integrated MIMs. The organogels were prepared via thermally initiated free radical polymerization, and $\mathrm{Cu}(\mathrm{I})$ metal was added in $\mathrm{MeOH}$ to pre-treated, swollen gels. De-metalation of the gels was achieved by adding cyanide salts and washing the gels. Changes in Young's and shear moduli, as well as tensile strength, were quantified through oscillatory shear rheology and tensile testing. The reported approach provides a general method for post-gelation tuning of mechanical properties using metals and well-defined catenane topologies as part of a network architecture.
\end{abstract}

Mechanically interlocked molecules (MIMs) are defined by the permanent interlocking of two or more molecules that can only be separated by breaking covalent bonds. ${ }^{1}$ Their unique structures have attracted the attention of chemists over the years, leading to the synthesis of various catenanes, ${ }^{2}$ rotaxanes, ${ }^{3,} 4$ knots $^{5-7}$ and molecular machines ${ }^{8}$-including those used in applications such as molecular pumps ${ }^{9}, 10$ and elevators. ${ }^{11}$ Catenanes (Fig. 1a) are mechanically interlocked macrocycles that are particularly interesting within the field of MIMs because of the number of conformational motions inherent to such architectures, ${ }^{12}$ e.g., elongation, rocking, and circumrotation (Fig. 1b). Translating these innate degrees of freedom to higher molecular weight polymers and materials has been a focus over the past two decades, with emphasis on synthesizing either poly[2]catenanes with covalent linkers in between mechanical bonds, or pure poly $[n]$ catenanes, where each link in the polymer backbone is held together through mechanically bonded macrocycles. ${ }^{13-15}$ De Bo and coworkers also showed that even a single [2] catenane in a polymer can increase the amount of stress and strain that a material can withstand compared to polymers composed only of linear backbones. ${ }^{16}$

In the context of gel networks, poly $[n]$ rotaxanebased slide-ring gels ${ }^{3}, 17,18$ are investigated more often

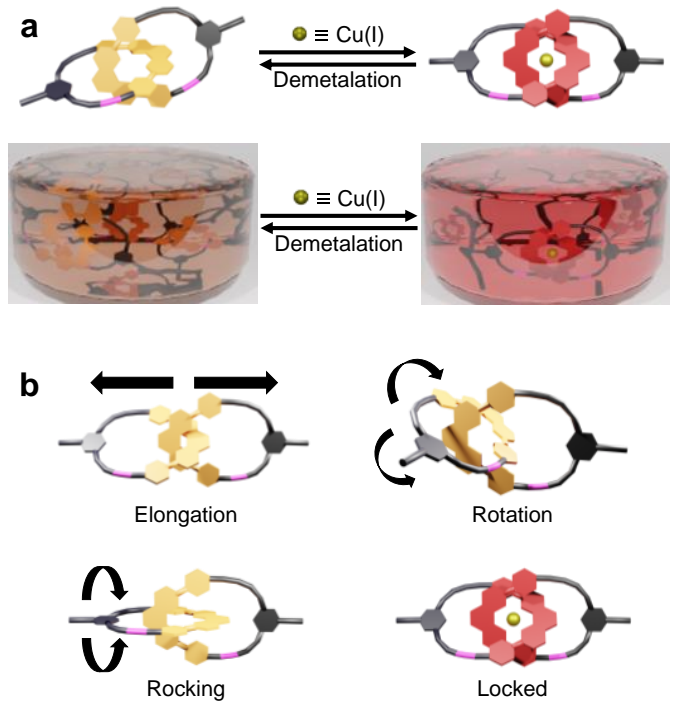

Figure 1. (a) Metal-based control over conformational motions of a [2]catenane-based crosslinker in a hydrogel network. (b) Different types of conformational motions accessible by a [2] catenane relative to a "locked" $\mathrm{Cu}(\mathrm{I})$-[2]catenate. 


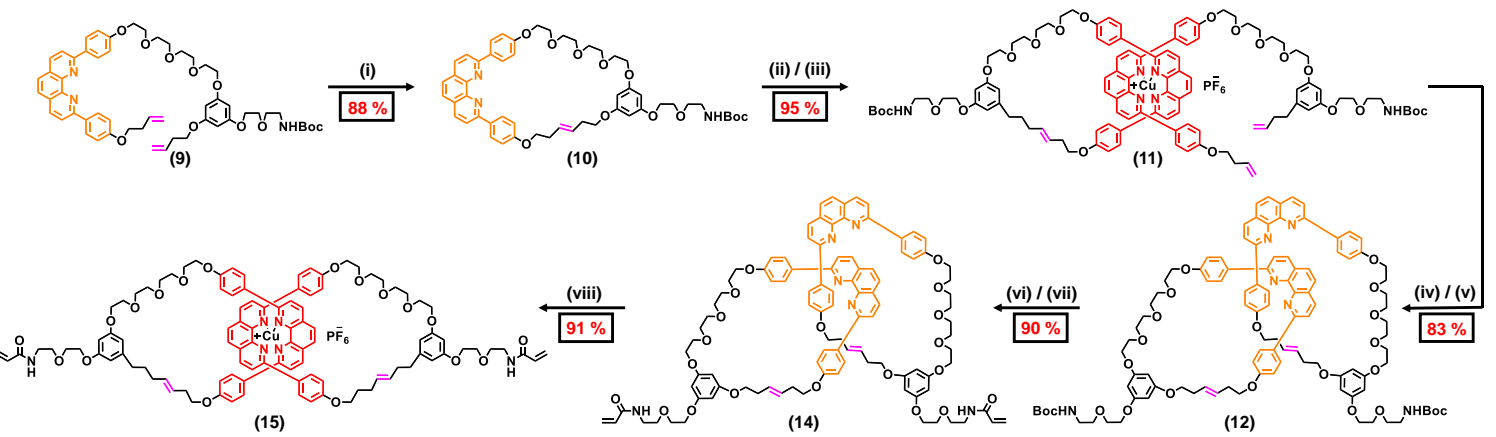

Scheme 1. Synthesis of [2] catenane-based crosslinker 14. (i) Grubbs $2^{\text {nd }}, \mathrm{CH}_{2} \mathrm{Cl}_{2}, 50{ }^{\circ} \mathrm{C}$, $48 \mathrm{~h}$; (ii) $\left[\mathrm{Cu}\left(\mathrm{CH}_{3} \mathrm{CN}\right)_{4}\right] \cdot \mathrm{PF}_{6}$, $\mathrm{CH}_{3} \mathrm{CN}, \mathrm{rt}, 15 \mathrm{~min}$; (iii) (9), $\mathrm{CH}_{3} \mathrm{CN}, \mathrm{rt}, 1 \mathrm{~h}$; (iv) Grubbs $2^{\text {nd }}, \mathrm{CH}_{2} \mathrm{Cl}_{2}, 50{ }^{\circ} \mathrm{C}, 24 \mathrm{~h}$; (v) $\mathrm{KCN}, \mathrm{CH}_{3} \mathrm{CN}_{2} \mathrm{H}_{2} \mathrm{O}, \mathrm{rt}, 1 \mathrm{~h}$; (vi) TFA, $\mathrm{CH}_{2} \mathrm{Cl}_{2}, 0^{\circ} \mathrm{C}$, $4 \mathrm{~h}$; (vii) acryloyl chloride, $\mathrm{Et}_{3} \mathrm{~N}, \mathrm{CHCl}_{3}, 0^{\circ} \mathrm{C}$, $4 \mathrm{~h}$; (viii) $\left[\mathrm{Cu}\left(\mathrm{CH}_{3} \mathrm{CN}\right)_{4}\right] \cdot \mathrm{PF}_{6}$, sodium ascorbate, $\mathrm{CH}_{2} \mathrm{Cl}_{2}, \mathrm{MeOH}$, $0{ }^{\circ} \mathrm{C}, 2 \mathrm{~h}$.

than gels composed of well-defined $[n]$ catenanes, which are less common. Even still, Huang and co-workers ${ }^{19}$ demonstrated how incorporation of a small quantity of pH-responsive [2]catenane crosslinker into a gel can lead to drastic changes in the material's stiffness, while conversely, Sato and co-workers recently imbued metalorganic crystals with elastic properties by establishing flexible [2]catenanes as the backbone of the framework. ${ }^{20}$ Thus, the lasting topology of $[n]$ catenanes allows for post-synthetic and physical modifications of soft materials, whilst not changing the overall network connectivity. Herein, we describe a novel post-gelation strategy for tuning the mechanical properties of gels using phenanthroline (phen)-based [2]catenanes as topologically well-defined crosslinkers that may be metalated reversibly with $\mathrm{Cu}(\mathrm{I})$, thus "locking" the conformational motions of the crosslinker. Subsequent removal of the metal allowed for free rotation about the mechanical bonds. The changes in physical properties were quantified by oscillatory shear rheology and tensile testing, and the results were compared to non-catenanecrosslinked gels that served as control samples.

Synthesis of the [2]catenane-based crosslinker (14) began with a convergent synthesis (Schemes S1S9) to make compound 9 . Grubbs $2^{\text {nd }}$ generation catalyst was then used to ring close 9 (Scheme 1, i), yielding $\mathbf{1 0 .}$ A slight excess of $\mathrm{Cu}(\mathrm{I})$ was added (ii) to $\mathbf{1 0}$ as $\left[\mathrm{Cu}\left(\mathrm{CH}_{3} \mathrm{CN}\right)_{4}\right] \cdot \mathrm{PF}_{6}$ to form an air-sensitive monometalated intermediate, ${ }^{21}$ which appeared as an orangecolored solution. Upon addition of open macrocycle 9 to $\mathbf{C u} \mathbf{1 0}$ (iii), the color of the solution changed to dark red, indicating formation of an air-stable ternary complex (11). This coordination complex was converted to $\mathbf{1 2}$ through another RCM reaction (iv), ${ }^{22}$ followed by removal of the metal center using KCN (v). Although the internal olefin of $\mathbf{1 1}$ could also potentially react during the ring closing (iv) step to form the [2]catenate, hydrogenation was not performed as it was often lower yielding because of hydrogenation of the $\mathrm{N}$ to $\mathrm{C}$ double bonds in the phen ligand. ${ }^{23}$ Compound 12 was deprotected using trifluoroacetic acid (13, Scheme S13), and the functional crosslinker was generated by adding acryloyl chloride to obtain catenane 14 in $90 \%$ yield. The purity of 14 was confirmed by ${ }^{1} \mathrm{H}$ NMR and HPLC (Fig. S27).

The [2] catenane crosslinker, 14, shows small changes in the ${ }^{1} \mathrm{H}$ NMR spectra (Fig. 2) when compared to macrocycle 10. While the splitting patterns of the diagnostic phen peaks change subtly, significant upfield shifting is observed for proton resonances labeled 1-3, 5, and $\mathrm{C}$ because of shielding in the interlocked molecule. Moreover, proton $\mathrm{C}$ splits into two signals, which may be attributed to the olefins residing inside the other mechanically bound macrocycle. Proton resonances 3-5 shift further upfield upon formation of the $\mathrm{Cu}(\mathrm{I})$ complex, 15. Formation of $\mathbf{1 5}$ was further corroborated by UV-Vis spectroscopy (Fig. S25), where diagnostic peaks from 450-600 $\mathrm{nm}$ were observed, indicating the metal-toligand charge transfer between the $\mathrm{Cu}(\mathrm{I})$ ion and the phen ligands. ${ }^{24}$ Formation of the dative bonds between the phen ligands and the $\mathrm{Cu}(\mathrm{I})$ ion is a critical aspect of controlling the catenane topology in the gel network (vide infra). It is important to note that a small subpopulation, approximately 14 Da less than the desired product, was observed via low-resolution mass spectrometry during characterization. This difference in mass is attributed to isomerization of the terminal alkene during RCM, resulting in loss of a methylene unit. This has been observed previously in $\mathrm{RCM}^{25}$ and is commonplace in the synthesis of small and oligocatenanes. ${ }^{26,27}$ After complete characterization, 14 was incorporated into organogels to evaluate the extent to which control over the crosslinker's conformational motions impacted the gel's mechanical properties.

Gels were synthesized (Fig. 3a) by dissolving 2methoxyethylacrylate (MEA), 14, and ammonium persulfate (APS) in DMSO, on a $4 \mathrm{wt} \%$ basis of 14 (Table S1). The pre-gel solution was vortexed to ensure compete mixing, and then pipetted into molds and cured at $80{ }^{\circ} \mathrm{C}$ for $25 \mathrm{~min}$. It should be noted that gels could not be synthesized with the metal-containing catenate crosslinker 15 because oxidation of $\mathrm{Cu}(\mathrm{I})$ competed with homolytic formation of radicals necessary to initiate/propagate the polymerization. ${ }^{28}$ After the 


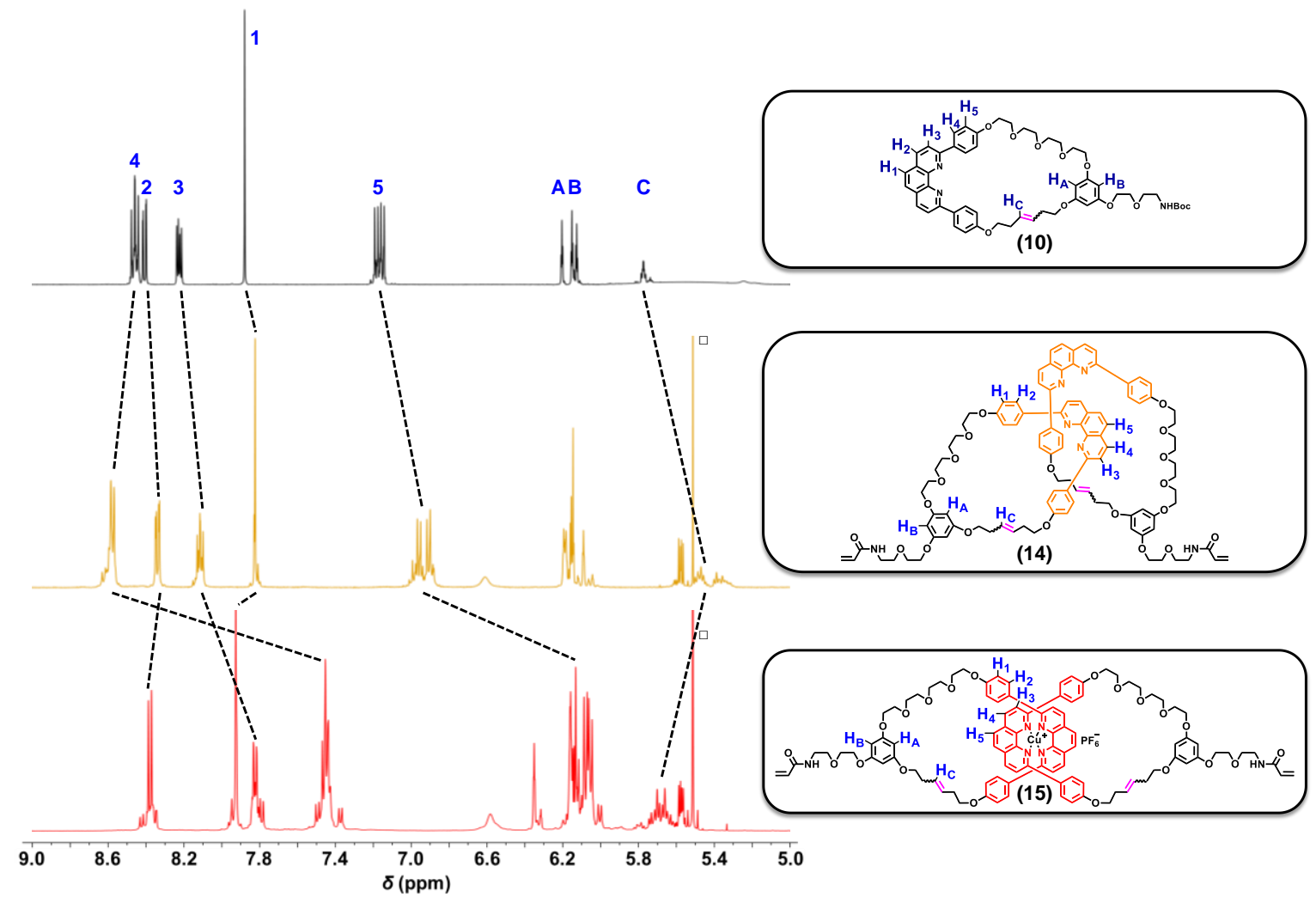

Figure 2. ${ }^{1} \mathrm{H}$ NMR $\left(\mathrm{CD}_{3} \mathrm{CN}, 25{ }^{\circ} \mathrm{C}, 128\right.$ scans) of Boc-protected macrocycle (10), [2]catenane (14), and $\mathrm{Cu}[2] \mathrm{catenate}$ (15). $\square-\mathrm{CH}_{2} \mathrm{Cl}_{2}$.

polymerization had gone to completion, the gels were swelled in $\mathrm{MeOH}$ to remove the DMSO, followed by treatment with a base (LiCN/KCN salts) to remove any residual protons from the phen ligands. These protons were acquired during the crosslinker acrylation step, wherein $\mathrm{HCl}$ was generated as a by-product, resulting in the as-synthesized gel appearing (Fig. 3b) yellow in color. Cyanide salts were used as the base in this step because they were later used to efficiently remove bound $\mathrm{Cu}(\mathrm{I})$ from the phen-phen complexes, resulting in translucent gels. The treated gels were then subjected to oscillatory shear rheology and tensile testing (vide infra).

After assessing the mechanical properties of the treated, as-synthesized gels, $\mathrm{Cu}(\mathrm{I})$ metal was readily incorporated into the crosslinker via soaking the gels in a $\mathrm{N}_{2}$-sparged solution of $\left[\mathrm{Cu}\left(\mathrm{CH}_{3} \mathrm{CN}\right)_{4}\right] \cdot \mathrm{PF}_{6}$ and sodium ascorbate in $\mathrm{MeOH}$ (Fig. 3a-b). Addition of the metal caused the colorless gels to appear red, indicating successful complexation. Next, the gels were soaked in an ethylenediaminetetraacetic acid (EDTA) solution to remove any excess metal not bound by the phens of the crosslinker before measuring the changes in the gels' mechanical properties. It is noteworthy that EDTA only removes residual metal ions and not those complexed by the phen ligands. This selectivity was confirmed in solution for 15 by ${ }^{1} \mathrm{H}$ NMR (Figs. S22) and UV-Vis spectroscopy (Fig. S26).
Removal of $\mathrm{Cu}(\mathrm{I})$ from the gels was performed by soaking them in a $\mathrm{LiCN}$ or $\mathrm{KCN}$ solution of MeOH for 2 h. A visible color change was observed (Fig. $3 \mathrm{~b}$ ), as the red color from the metal-ligand interaction was disrupted. The use of LiCN instead of the more readily available KCN was necessary because the latter gave inconsistent results during tensile testing, such as increased elongation at break and diminished tensile strength. We hypothesize the reason for these inconsistencies is because the de-metalated crosslinker (14) can coordinate the larger $\mathrm{K}^{+}$cations better than $\mathrm{Li}^{+}$ cations. To test this hypothesis, two sets of gels crosslinked by 14 were treated separately with $\mathrm{KCl}$ and $\mathrm{LiCl}$ solutions. The KCl-treated gels exhibited increased elongation at break and decreased tensile strength, whereas the gels treated with $\mathrm{LiCl}$ did not experience significant changes. Furthermore, polyMEA was synthesized (Scheme S17) and treated with KCN as a control experiment (Scheme S18) to demonstrate that changes in the mechanical properties were not due to $\mathrm{KCN}$-induced degradation of the polymer backbone in the gel. The lack of degradation was confirmed by ${ }^{1} \mathrm{H}$ and ${ }^{13} \mathrm{C}$ NMR spectroscopy (Fig. S23-24). 


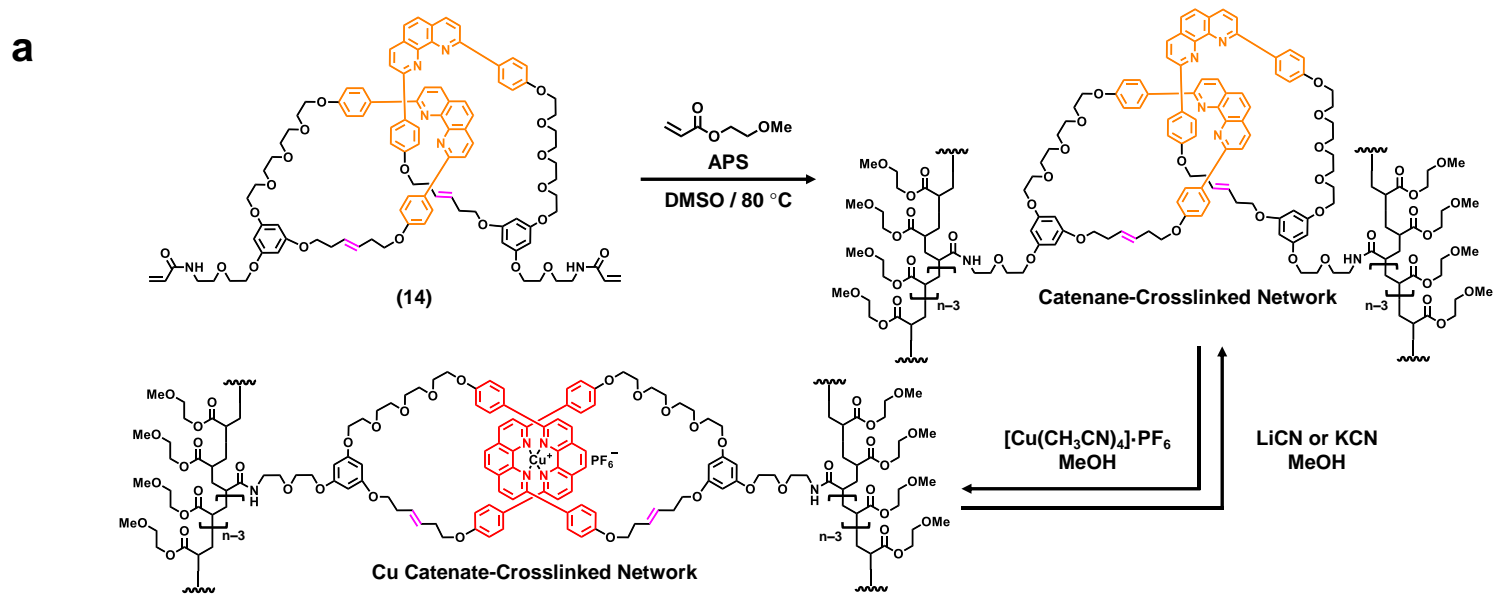

b

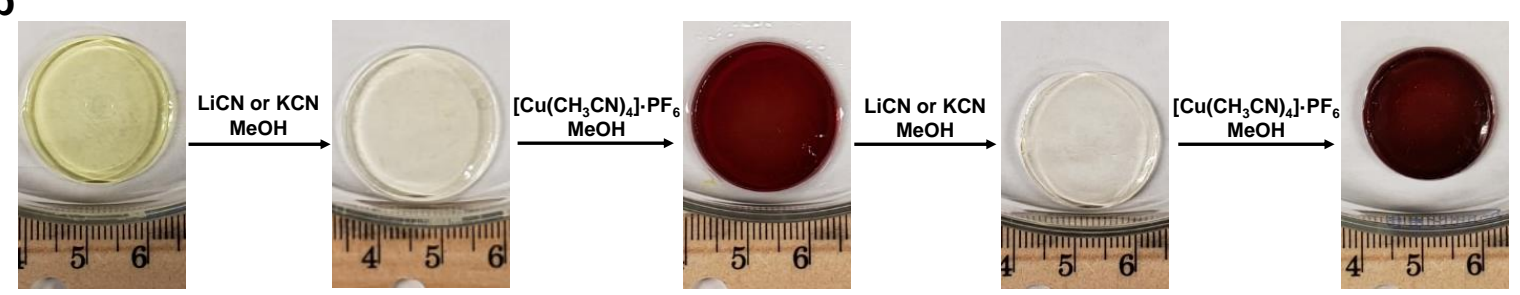

Figure 3. (a) Scheme describing incorporation of the [2]catenane-based crosslinker 14 into a MEA-based organogel, followed by post-synthetic modification of a gel network using metalation/de-metalation. (b) Pictures of gels cycled between treatments. The ruler scale is in centimeters.

Oscillatory shear rheology was performed on 8 $\mathrm{mm}$ diameter disc-shaped punches obtained from each of the catenane-crosslinked gels. The cyanide-treated, as-synthesized gels yielded four punches in total. Notable changes in the storage $\left(G^{\prime}\right)$, loss $\left(G^{\prime \prime}\right)$, and complex shear $\left(G^{*}\right)$ moduli were observed (Table 1) for the $\mathrm{Cu}(\mathrm{I})$-metalated gels versus the as-synthesized gels, and for those de-metalated via KCN treatment. Specifically, $G^{\prime}$ increased $11.6 \%$ in going from the assynthesized gel to the $\mathrm{Cu}(\mathrm{I})$-metalated gel, while $G^{\prime \prime}$ decreased by $50.1 \%$. Conversely, KCN treatment of the metalated gels decreased $G^{\prime}$ by $17.4 \%$ and increased $G^{\prime \prime}$ by $61.5 \%$. A second $\mathrm{Cu}(\mathrm{I})$ metalation step increased $G^{\prime}$ by $16.3 \%$ and decreased $G^{\prime \prime}$ by $39.6 \%$. Correspondingly, $G^{*}$ changed $\sim 20 \%$ after each step. We hypothesize that gels with a "locked" catenate conformation behave more like ideal elastic materials relative to their "freely rotating" catenane counterparts. The decrease in storage modulus for the de-metalated gels indicates that they are more viscous than the metal-containing, conformationally "locked" gels.

Dynamic tensile testing was used to quantify changes in Young's modulus (E) and tensile strength (TS) for each gel to corroborate the data obtained from shear rheology experiments. The trends observed for $E$ for each gel upon metalation/de-metalation match well with those observed for $G^{*}$, at least up until the second metalation step. However, physical degradation of the gels became evident after the second $\mathrm{Cu}(\mathrm{I})$ metalation step, meaning the data from mechanical testing beyond the first cycle became less reliable (Fig. S12-13).
Moreover, the trend for TS was also consistent over the first metalation step, i.e., a roughly $20 \%$ increase was observed, but the TS did not return to its original value after de-metalation (Table 1). As a control experiment, gels were synthesized using MEA and polyethylene glycol diacrylate (PEGDA) as the crosslinker. No changes in material properties were observed upon $\mathrm{Cu}(\mathrm{I})$ metalation of the PEGDA-crosslinked gels, confirming that the physical changes observed for the [2]catenanebased gels are related entirely to the topology of the crosslinker (Table S2).

In conclusion, a $\mathrm{Cu}(\mathrm{I})$-responsive [2]catenanebased crosslinker was synthesized, incorporated into organogels, and the mechanical properties of the material tested using oscillatory shear rheology and dynamic tensile testing to determine the role $\mathrm{Cu}(\mathrm{I})$ metalation/de-metalation played in the gels' mechanical properties. These gels were compared to PEGDAcrosslinked gels, the latter of which displayed no change in physical or mechanical properties upon metalation. Thus, the use of metals in a catenane-crosslinked gel network represents a novel strategy for changing the macroscale properties of the material without affecting its overall network connectivity. Future investigations will include incorporation of $[n]$ catenane crosslinkers into other more robust materials, as well as studies looking to improve the durability, and therefore cyclability, of the soft material. 


\begin{tabular}{c|ccccc} 
Treatment & ${ }^{a} \boldsymbol{E}(\boldsymbol{k P a})$ & ${ }^{b} \boldsymbol{G}^{*}(\boldsymbol{P a})$ & ${ }^{c} \boldsymbol{G}^{\prime}(\mathbf{P a})$ & ${ }^{d} \boldsymbol{G} \boldsymbol{G}^{\prime \prime}(\boldsymbol{P a})$ & ${ }^{\mathbf{e}} \boldsymbol{T S}(\boldsymbol{k P a})$ \\
\hline Li or KCN (A) & $55.2 \pm 8.5$ & $5069 \pm 446$ & $4654 \pm 280$ & $152 \pm 17$ & $41.6 \pm 3.5$ \\
Cu (A) & $66.7 \pm 1.9$ & $6029 \pm 492$ & $5193 \pm 248$ & $75 \pm 9$ & $49.7 \pm 2.6$ \\
Li or KCN (B) & $47.8 \pm 0.4$ & $4642 \pm 350$ & $4291 \pm 291$ & $122 \pm 9$ & $50.2 \pm 1.4$ \\
Cu (B) & $27.2 \pm 3.3$ & $5622 \pm 329$ & $4989 \pm 185$ & $74 \pm 4$ & $40.3 \pm 3.1$
\end{tabular}

Table 1. Summarized table of physical characteristics of [2] catenane-crosslinked gels during the first metalation step (A) and second de-metalation/re-metalation cycle (B). ${ }^{a}$ Young's modulus $(E)$, determined by the linear portion of the stress vs. strain curve. ${ }^{b}$ Complex shear modulus $\left(G^{*}\right)$, calculated from the ${ }^{c}$ storage $\left(G^{\prime}\right)$ and $d$ loss $\left(G^{\prime \prime}\right)$ moduli measured from shear rheology at $1 \%$ strain. ${ }^{e}$ Tensile Strength (TS), determined from the maximum stress value before break. Values are the average of experiments completed in three-fold repetition.

\section{ASSOCIATED CONTENT}

Supporting Information

Synthesis and characterization data (i.e., nuclear magnetic resonance (NMR), UV-vis optical absorption spectroscopy, mass spectrometry (MS), oscillatory shear rheology and dynamic tensile testing. The Supporting Information is available free of charge on the ACS Publications website as a single PDF.

\section{ACKNOWLEDGMENTS}

Funding support was provided by the David and Lucile Packard Foundation through J.C.B.'s Packard Fellowship for Science and Engineering. M.S.P. acknowledges support from the Department of Defense (DoD) through the National Defense Science \& Engineering Graduate (NDSEG) Fellowship program. A.O.D. acknowledges support from the National Science Foundation Graduate Research Fellowship Program (NSF GRFP; DGE-1745038) and PEO International Scholar Award. The rheological and tensile data were obtained through the Department of Mechanical Engineering and Materials Science at WUSTL.

\section{AUTHOR INFORMATION}

Corresponding Author

jcbarnes@wustl.edu

Notes

The authors have filed a non-provisional patent containing part of the work described in this manuscript.

\section{REFERENCES}

1. Stoddart, J. F., The chemistry of the mechanical bond. Chem. Soc. Rev. 2009, 38 (6), 1802-1820.

2. Gil-Ramirez, G.; Leigh, D. A.; Stephens, A. J., Catenanes: Fifty Years of Molecular Links. Angew. Chem. Int. Ed. 2015, 54 (21), 6110-6150.

3. Xue, M.; Yang, Y.; Chi, X. D.; Yan, X. Z.; Huang, F. H., Development of Pseudorotaxanes and Rotaxanes: From Synthesis to Stimuli-Responsive Motions to Applications. Chem. Rev. 2015, 115 (15), 73987501.
4. Gotoh, H.; Liu, C.; Bin Imran, A.; Hara, M.; Seki, T.; Mayumi, K.; Ito, K.; Takeoka, Y., Optically transparent, high-toughness elastomer using a polyrotaxane cross-linker as a molecular pulley. Sci. Adv. 2018, 4 (10).

5. Forgan, R. S.; Sauvage, J. P.; Stoddart, J. F., Chemical Topology: Complex Molecular Knots, Links, and Entanglements. Chem. Rev. 2011, 111 (9), 54345464.

6. Guo, J.; Mayers, P. C.; Breault, G. A.; Hunter, C. A., Synthesis of a molecular trefoil knot by folding and closing on an octahedral coordination template. Nat. Chem. 2010, 2 (3), 218-222.

7. Ponnuswamy, N.; Cougnon Fabien, B. L.; Clough Jessica, M.; Pantoş, G. D.; Sanders Jeremy, K. M., Discovery of an Organic Trefoil Knot. Science 2012, 338 (6108), 783-785.

8. Erbas-Cakmak, S.; Leigh, D. A.; McTernan, C. T.; Nussbaumer, A. L., Artificial Molecular Machines. Chem. Rev. 2015, 115 (18), 10081-10206.

9. Cheng, C. Y.; McGonigal, P. R.; Schneebeli, S. T.; Li, H.; Vermeulen, N. A.; Ke, C. F.; Stoddart, J. F., An artificial molecular pump. Nat. Nanotechnol. 2015, 10 (6), 547-553.

10. Feng, L.; Qiu, Y.; Guo, Q.-H.; Chen, Z.; Seale James, S. W.; He, K.; Wu, H.; Feng, Y.; Farha Omar, K.; Astumian, R. D.; Stoddart, J. F., Active mechanisorption driven by pumping cassettes. Science 2021, DOI: 10.1126/science.abk1391.

11. Badjic, J. D.; Balzani, V.; Credi, A.; Silvi, S.; Stoddart, J. F., A molecular elevator. Science 2004, 303 (5665), 1845-1849.

12. Mena-Hernando, S.; Perez, E. M., Mechanically interlocked materials. Rotaxanes and catenanes beyond the small molecule. Chem. Soc. Rev. 2019, 48 (19), 5016-5032.

13. Weidmann, J. L.; Kern, J. M.; Sauvage, J. P.; Muscat, D.; Mullins, S.; Kohler, W.; Rosenauer, C.; Rader, H. J.; Martin, K.; Geerts, Y., Poly[2]catenanes and cyclic oligo[2]catenanes containing alternating topological and covalent bonds: Synthesis and characterization. Chem. Eur. J. 1999, 5 (6), 18411851.

14. Hagiwara, T.; Murano, Y.; Watanabe, Y.; Hoshi, T.; Sawaguchi, T., Catenane gel: synthesis of high molecular weight poly[2]catenanes by Sonogashira 
coupling polymerization. Tetrahedron Lett. 2012, 53 (23), 2805-2808.

15. Rauscher, P. M.; Rowan, S. J.; de Pablo, J. J., Topological Effects in Isolated Poly[n]catenanes: Molecular Dynamics Simulations and Rouse Mode Analysis. ACS Macro Lett. 2018, 7 (8), 938-943.

16. Zhang, M.; De Bo, G., A Catenane as a Mechanical Protecting Group. J. Am. Chem. Soc. 2020, 142 (11), 5029-5033.

17. Okumura, Y.; Ito, K., The polyrotaxane gel: A topological gel by figure-of-eight cross-links. $A d v$. Mater. 2001, 13 (7), 485-+.

18. Wang, W. C.; Zhao, D. T.; Yang, J. N.; Nishi, T.; Ito, K.; Zhao, X. Y.; Zhang, L. Q., Novel Slide-Ring Material/Natural Rubber Composites with High Damping Property. Sci. Rep. 2016, 6.

19. Xing, H.; Li, Z. T.; Wu, Z. L.; Huang, F. H., Catenane Crosslinked Mechanically Adaptive Polymer Gel. Macromol. Rapid Comm. 2018, 39 (1).

20. Meng, W.; Kondo, S.; Ito, T.; Komatsu, K.; Pirillo, J.; Hijikata, Y.; Ikuhara, Y.; Aida, T.; Sato, H., An elastic metal-organic crystal with a densely catenated backbone. Nature 2021, 598 (7880), 298-303.

21. Dietrichbuchecker, C. O.; Sauvage, J. P.; Kern, J. M., Templated Synthesis of Interlocked Macrocyclic Ligands - the Catenands. J. Am. Chem. Soc. 1984, 106 (10), 3043-3045.

22. Weck, M.; Mohr, B.; Sauvage, J. P.; Grubbs, R. H., Synthesis of catenane structures via ring-closing metathesis. J. Org. Chem. 1999, 64 (15), 5463-5471.

23. Eckhard, I. F.; Fielden, R.; Summers, L. A., Hydrogenation of 1,10-Phenanthroline. Aust. J. Chem. 1975, 28 (5), 1149-1151.

24. Niess, F.; Duplan, V.; Sauvage, J.-P., Interconversion between a Vertically Oriented Transition MetalComplexed Figure-of-Eight and a Horizontally Disposed One. J. Am. Chem. Soc. 2014, 136 (16), 5876-5879.

25. Monfette, S.; Fogg, D. E., Equilibrium Ring-Closing Metathesis. Chem. Rev. 2009, 109 (8), 3783-3816.

26. Berrocal, J. A.; Pitet, L. M.; Nieuwenhuizen, M. M. L.; Mandolini, L.; Meijer, E. W.; Di Stefano, S., RingOpening Metathesis Polymerization of a Diolefinic [2]-Catenane-Copper(I) Complex: An Easy Route to Polycatenanes. Macromolecules 2015, 48 (5), 13581363.

27. Colley, N. D.; Nosiglia, M. A.; Li, L.; Amir, F.; Chang, C.; Greene, A. F.; Fisher, J. M.; Li, R. H.; Li, X. S.; Barnes, J. C., One-Pot Synthesis of a Linear [4]Catenate Using Orthogonal Metal Templation and Ring-Closing Metathesis. Inorg. Chem. 2020, 59 (15), 10450-10460.

28. Zhou, P.; Zhang, J.; Liang, J.; Zhang, Y. L.; Liu, Y.; Liu, B., Activation of persulfate/copper by hydroxylamine via accelerating the cupric/cuprous redox couple. Water Sci. Technol. 2016, 73 (3), 493500 . 